Chapter 26

\title{
The Role of Knee Arthrodesis After TKA Infection
}

\author{
Pablo Renovell, Antonio Silvestre and \\ Oscar Vaamonde \\ Additional information is available at the end of the chapter \\ http://dx.doi.org/10.5772/53690
}

\section{Introduction}

Infection after total knee arthroplasty (TKA) is a devastating complication posing substantial clinical and financial burden, which incidence is increasing in line with the rise of the number of TKAs performed worldwide. The incidence of this complication rates from $1 \%$ in primary TKAs to $5.8 \%$ after TKAs revision in long series [1]. The lowest reinfection rate after a prior reimplantation for septic TKA has been reported near 30\% [2].

The goals in the treatment of chronic infected TKA are control of the disease and restoring knee function. Alternative techniques in the management of reinfected knee prosthesis are another two-stage prosthesis reimplantation, arthrodesis, resection arthroplasty, and supracondylar amputation [3]. Although two-stage surgery is generally believed as the most successful decision, chronic infection forces surgeons to look for other alternatives.

Recurring infection at the site of a total knee arthroplasty should be treated by knee arthrodesis unless control of the disease and good functional recover could be possible [4]. Arthrodesis of the knee can provide a stable painless joint for an independent lifestyle that would not be possible after a failed total knee replacement. Whereas reimplantation of a TKA shows better limb function, arthrodesis achieves better pain relief, not finding significant differences in knee scores between the two procedures (Oxford knee score) [5, 6]. Knee arthrodesis can be achieved with a cemented or uncemented intramedullary nail, inserted from great trochanter or through the knee, with two plates applied in two planes or using an external fixator to produce a joint fusion [4]. Intramedullary nails provide greater stability, avoid pin-track infection, allow faster weight bearing and generally are better accepted by the patients than external fixators [7]. Illizarov method is more desirable when soft tissues conditions are poor or after failing of intramedullary nail $[8,9]$. 
There are few and short series of cemented modular nail for knee arthrodesis after TKA infection in literature $[10,11]$. The purpose of this study is to report the role of knee arthrodesis after chronic infection of knee prostheses and show our results with the use of a modular cemented nail inserted through the knee.

\section{Material and methods}

We review retrospectively twenty-one patients who have undergone knee arthrodesis with a cemented modular nail for chronic infection of knee prosthesis, from January 2003 until January 2011 in our Department. Three senior surgeons performed all procedures.

Endo-Model ${ }^{\circledR}$ Knee Fusion Nail (Newsplint, UK/Waldemar Link ${ }^{\circledR}, \mathrm{GmbH} \&$ Co. KG, Hamburg, Germany) was used in all cases. Twelve of those cases received previous surgery in our Hospital (a reference institution for knee reconstruction) but the other nine cases came from others Hospitals. The decision to undertake knee fusion was arranged after analyzing the different options with the patient.

The first surgical stage was exhaustive debridement and placement of a double antibioticloaded (clindamycin and gentamicin) bone cement as a static spacer (Rofabacin ${ }^{\circledR}$ Revision, Biomet $\left.{ }^{\circledR}\right)$. Systemic antibiotics according to the culture results were given to the patients for at least six weeks. When the patient was recovered from the first-stage surgery, no signs of infection were observed and values of inflammatory markers (PCR and ESR) were decreased, the cemented modular nail was inserted through the knee after reaming tibial and femoral canals. Tibial and femur implants are cemented with antibiotic loaded cement. Nineteen cases were performed according to this two-stage procedure, but two cases were done in just one-stage.

Hospital records and serial radiographies of all patients were reviewed to evaluate patient status and outcomes. We have excluded a patient lost on follow-up.

Number of previous surgeries per patient, comorbidities and microorganisms responsible for the infection were recorded.

In order to assess functional outcome, the Oxford Knee Score (OKS) [12] was checked before removal of the implants and at final follow-up. Successful outcome was defined as not or slight pain on the operated limb and able to walk with or without aids at the time of the last follow-up.

\section{Results}

Twenty-one patients were treated with cemented modular nail for knee arthrodesis from 2003 to 2011 for chronic infection of the prostheses (Figure 1.). One patient was lost during followup and was excluded from this series. Mean follow-up of patients was 3.2 years (range, six months to eight years). 


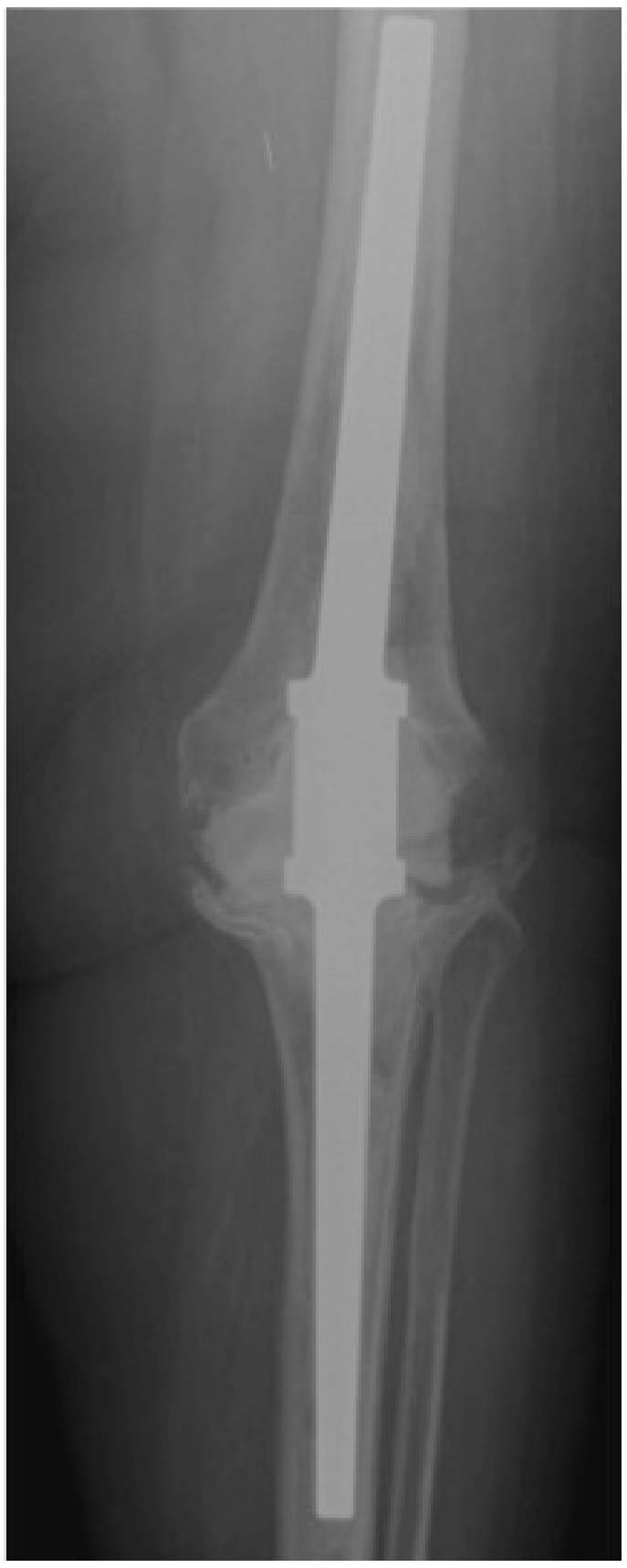

Figure 1. Cemented modular nail for knee arthrodesis. 
Twenty patients were fully recorded. The series includes eleven women and nine men with a mean age of seventy-six years (range 68-86 years) at the time of arthrodesis. Time since primary knee arthroplasty until knee arthrodesis, ranged from eight months to nine years (mean 4.4 years). The number of procedures carried out before definitive arthrodesis ranged from 2 to 7 (mean 3.3 surgeries).

Most frequent comorbidities were hypertension (65\%), obesity [BMI $\left.>30 \mathrm{~kg} / \mathrm{m}^{2}\right](45 \%)$ and Diabetes Mellitus (40\%). Demographics of the patients are shown in Table 1.

\begin{tabular}{lc}
\hline Number of patients fully recorded & 20 \\
\hline Age & $76.8 \pm 10.2$ \\
\hline Sex (M/F) & $11 / 9$ \\
\hline Side (R/L) & $12 / 8$ \\
\hline Body mass index $\left(\mathbf{K g} / \mathbf{m}^{2}\right)$ & $29.8 \pm 1.4$ \\
\hline Comorbidities & $13(65 \%)$ \\
\hline HTA & $9(45 \%)$ \\
Obesity & $8(40 \%)$ \\
\hline DM & $3.3(2-7)$ \\
\hline Mean no of knee prior surgeries & $17.1(9-32)$ \\
\hline Preoperative OKS & \\
\hline
\end{tabular}

Table 1. Demographics of the study population

Intraoperative cultures were positive on 19 cases (95\%). In eight of the cases (40\%) only one bacteria could be checked, but on the other hand two or more microorganisms yielded on cultures in eleven cases (55\%). The predominant microorganisms were staphylococcus epidermidis in 11 cases (55\%) and staphylococcus aureus in 7 cases (35\%), 10 of which (8 s. epidermidis and 2 s.aureus) were methicillin-resistant staphylococcus (MRS), so we can conclude that $50 \%$ of fused knees were positive to MRS. Other microorganism included in this series was Escherichia coli in 4 cases (20\%).

Fifteen patients $(75 \%)$ healed without problems and they did not need more surgeries, four (20\%) showed inadequate control of infection so required new performances (one case onestage debridement, two arthrodesis with external fixators and one case supracondylar amputation), and two cases (10\%) suffered a tibial shaft fracture below the tip of the nail. One of the fractures was resolved changing the nail for a longer one (Figure 2), and the other was treated with immobilization. Two of the four cases (50\%) with persistence of of infection were operated in one-stage surgery. 


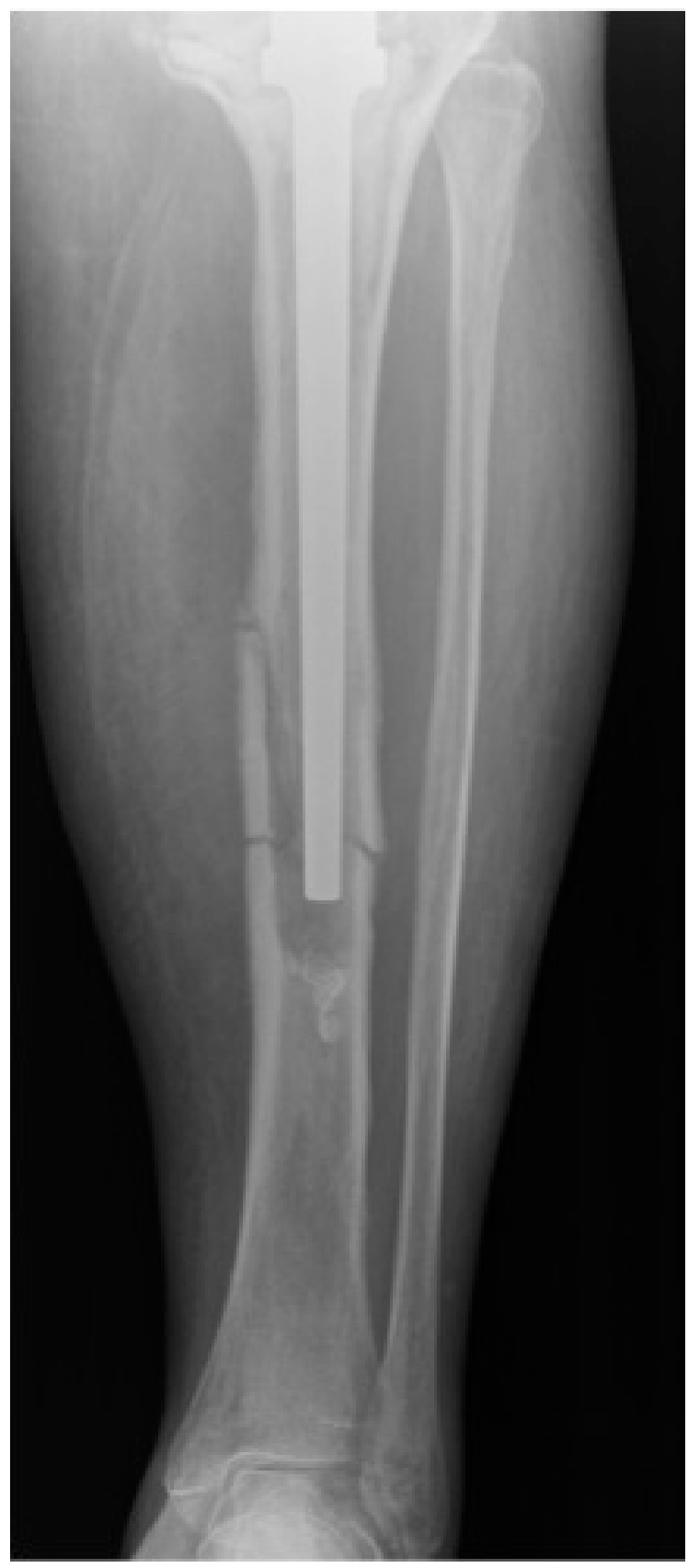

Figure 2. Tibia fracture and bone loosening below the nail. 
The mean Oxford knee score improved from 17.1 points (range, 9 to 32 points) before removal of the prosthesis, to 27.4 points (range, 6 to 41 points) postoperatively. Successful outcome was $95 \%$ at the time of the last follow-up. Results of the series are shown in Table 2.

\begin{tabular}{|c|c|}
\hline Number of cases infected by MRS & $10(50 \%)$ \\
\hline Patients healed without problems & $15(75 \%)$ \\
\hline \multicolumn{2}{|l|}{ Causes of reoperations } \\
\hline Persistent infection & $4(20 \%)$ \\
\hline \multicolumn{2}{|l|}{$\begin{array}{l}\text { Fracture on tibia below the nail } \\
\text { (and bone loosening) }\end{array}$} \\
\hline \multicolumn{2}{|l|}{ Reoperations } \\
\hline \multicolumn{2}{|l|}{ Arthrodesis with external fixator 2} \\
\hline One-stage debridement & 1 \\
\hline Supracondylar amputation & 1 \\
\hline Change for a longer nail & 1 \\
\hline Postoperative OKS & $27.4(6-41)$ \\
\hline
\end{tabular}

Table 2. Results of knee arthrodesis with cemented modular nail

\section{Discussion}

The reason to turn a TKA into arthrodesis due to a chronic infection is not clear nowadays, and the decision-making process is sometimes difficult. When a second infection happens, the number of surgeries performed in the knee reaches until 9.3 of average [1], so this detail must be always present on surgeon's mind when re-infection occurs. Infection of primary TKA has been related with hyperglycaemia, prolonged operative time, obesity, rheumatoid arthritis and others [1], however in TKA reinfection, the main factors related to this condition are previous infection with tough microorganisms, poor soft tissue coverage and number of previous surgeries [2].

Although surgeon might consider joint fusion as a poor result, comparing to other choices, knee with a fusion is more efficient and functional [13]. Supracondylar amputation as a consequence of a failed total knee revision arthroplasty is a salvage procedure in front of a severe infection, uncontrolled pain or massive bone loss. This radical surgery should not be related knee prosthesis complications but to peripheral vascular disease or recurrence of a malignant tumor [14]. Functional outcome after supracondylar amputation carried out ought to an infected total knee replacement is poor. Patients with a supracondylar amputation after chronic infection of prosthesis show low functional status. Only $50 \%$ of these patients are able to walk after the surgery [15]. The awful OKS of our amputated patients (6 points), confirms this fact. 
The alternative of resection arthroplasty in case of recalcitrant TKA infection is only an option when the patient previously was not able to walk, due to a medical infirmity or other limb pathology. Results on pain and functional scores are always lower than two-stage reimplatation or arthrodesis [16].

Clinical outcomes of revision TKA after aseptic loosening are better than knee prosthesis revision after chronic infection [17]. Wang et al [5] asserted, comparing clinical outcomes of the different alternatives in the treatment of infected TKA, that Oxford Knee Score after revision TKA is similar to knee arthrodesis. He reported just about mild-to-moderate knee pain on almost $50 \%$ of the reimplanted TKAs. Knee arthrodesis shows better pain relief but worse function than revision TKA, whereas reimplanted TKA reveals better function and worse pain relief than knee fusion. Anyway, knee arthrodesis allows the patient an independent lifestyle with few complications [18]. And it is important to keep in mind that re-infection rate after TKA revision is $68.6 \%$, lessen to $52.6 \%$ in case of resistant microorganisms [2]. The rate can be reduced to only $18 \%$ when these microorganisms are identified and properly treated [19]. Maheshwari et al [2] reported that supracondylar amputation was performed on $14.2 \%$ of his cases, whereas only on $5.7 \%$ of his patients arthrodesis was the final operation. Our results show that infection was controlled in $75 \%$ of our patients with a knee arthrodesis done with a cemented modular nail and no more re-operations were needed. In our series, just one case of amputation was performed (5\%). We agree with others authors $[13,20]$ that after a second TKA infection due to high virulence microorganisms or after multiple attempts of failed revision arthroplasty, knee arthrodesis should be the therapeutic choice in most of the cases or at least in those cases with low functional demanding patients in order to avoid a possible supracondylar amputation.

The three most frequent surgical techniques used to achieved knee arthrodesis after failed TKA are internal plate fixation, intramedullary rod fixation and external fixation [4]. Subsequent conversion of a knee arthrodesis to a total knee arthroplasty is not advisable, as almost of the reimplanted arthroplasties fail [21, 22].

Internal plate fixation is rarely used to achieve knee fusion due to the requirement of a broad soft tissue exposure, long time weight-bearing and because of the incidence of pseudoarthrosis is high.

External fixation has been the method of choice to attained knee arthrodesis following chronic infected TKA [8, 9, 23-25]. Advantages of external fixation include the fact that produces proper bone compression, the surgical procedure can be performed in one operative stage, and no implants remain inside the body after the external fixator removal. These details presume less recurrent infection rate than other arthrodesis techniques. Problems related to this treatment are carrying the device for long periods of time, usually more than six months, the subsequent shortening of the limb, the pin site infection or the possibility of a fracture through the weakened bone [7]. Nowadays this alternative is used in chronic infected knees after arthrodesis with bad tolerance of the nail. [4]. Two of our patients (10\% of cases) needed an external fixator (Illizarov method) to achieve a useful limb. 
Intramedullary nail is actually the most widespread option to fuse the knee [4, 20, 26-29]. Rate of fusion near $100 \%$ has been well documented in literature, as well as the satisfactory results in case of persistent infection that rarely forces the surgeon to take out the nail [30]. Complications of intramedullary nail fixation include periprosthetic fracture, hardware-related pain, bone loosening and persistent infection. Arthrodesis performed with a nail should be done according to a two-staged protocol in order to reduce the incidence of reinfection. Two of our four cases $(50 \%)$, which showed inadequate infection control, were treated in first instance through a one-stage surgery; this fact supports previous reports and remarks the requirement of two stage-surgery to get a free-infected arthrodesis [4,31,32].

The preference of achieving knee fusion with an external fixator or with the aid of an intramedullary rod should be based on surgeon's experience and on the review of the advantages and disadvantages of each techniques [7].

There are different models of knee nails used to achieve arthrodesis. In the beginning long Küntscher nail was introduced through the great trochanter after debridement of the infected joint $[33,34]$. This double approach is rarely used nowadays, and is reserved to failures of previous arthrodesis, fractures of the tibia or femur or cases of bone loosening that requires extended fixation $[35,36]$. One patient $(5 \%)$ of our series needed this procedure.

Modular nail can be inserted through the knee and it is at the present time the most frequent surgical technique to achieve a knee fusion; it shows fusion rates of nearly $95 \%$ of cases [37-39]. Modular nails could be cemented or uncemented but there is no literature that compares results of these models. When an uncemented nail is used, maximum bone contact is extremely important in order to get knee arthrodesis and usually autologous bone graft is required. After using an uncemented device shortening of the limb is frequent, as occurs with external fixators. Fractures around the tip of the rod or the locked screws are possible [40], as well as loosening of the implant. Few reports and small number of cases with the use of cemented nails have been published, so hardly any conclusions about this procedure can be obtained [10, 11]. The technique of cementing the nail could avoid shortening of the limb, compensate bone loss and provide an artificial joint fusion without employing bone graft. Fractures around the nail are probably less frequent than in uncemented nails, but when cemented nails must be removed surgery is quite tougher and bone loss bone could be a problem for the revision surgeries. Neuerburg et al [11] have published a review with the same number of cases than us, with similar results and conclusions, advising of clinical and radiological follow-up to allow appropriate surgery in case of loosening.

\section{Conclusion}

Recurrent infection after a previously exchange arthroplasty for chronic infected TKA is a challenging problem. This devastating complication is associated to infection due to high virulence resistant microorganisms, poor soft tissue coverage and a high number of previous surgeries. When this complication occurs, surgeons must always have in mind the possibility of an above knee amputation as a final result if we insist on revising to a knee arthroplasty. In 
order to avoid this terrible result, knee arthrodesis, preferably in two-stages, could be an option to achieve a useful and stable painless limb. Among the different alternatives to obtain knee arthrodesis, we believe that the best procedure is inserting a cemented modular nail through the knee, which provides a strong fixation, has a low rate of reinfection and allows to restore the length of the limb though significant bone loss due to previous surgeries.

\section{Author details}

Pablo Renovell, Antonio Silvestre and Oscar Vaamonde

Orthopaedic Department. Hospital Clínico of Valencia, Spain

\section{References}

[1] Blom, A. W, Brown, J, Taylor, A. H, Pattison, G, Whitehouse, S, \& Bannister, G. C. Infection after total knee arthroplasty. J Bone Joint Surg Br. (2004). Jul;, 86(5), 688-91.

[2] Maheshwari, A. V, Gioe, T. J, Kalore, N. V, \& Cheng, E. Y. Reinfection after prior staged reimplantation for septic total knee arthroplasty: is salvage still possible? J Arthroplasty. (2010). Sep; 25(6 Suppl): , 92-7.

[3] Morrey, B. F, Westholm, F, Schoifet, S, Rand, J. A, \& Bryan, R. S. Long-term results of various treatment options for infected total knee arthroplasty. Clin Orthop Relat Res. (1989). Nov;(248): 120-8.

[4] Conway, J. D, Mont, M. A, \& Bezwada, H. P. Arthrodesis of the knee. J Bone Joint Surg Am. (2004). Apr;A(4):835-48., 86.

[5] Wang, C. J, Huang, T. W, Wang, J. W, \& Chen, H. S. The often poor clinical outcome of infected total knee arthroplasty. J Arthroplasty. (2002). Aug; , 17(5), 608-14.

[6] Husted, H. Toftgaard Jensen T. Clinical outcome after treatment of infected primary total knee arthroplasty. Acta Orthop Belg. (2002). , 68, 500-7.

[7] Mabry, T. M, Jacofsky, D. J, Haidukewych, G. J, \& Hanssen, A. Comparison of intramedullary nailing and external fixation knee arthrodesis for the infected knee replacement. Clin Orthop Relat Res. (2007). Nov; , 464, 11-5.

[8] Oostenbroek, H. J, \& Van Roermund, P. M. Arthrodesis of the knee after an infected arthroplasty using the Ilizarov method. J Bone Joint Surg Br. (2001). Jan;, 83(1), 50-4.

[9] Manzotti, A, Pullen, C, Guerreschi, F, \& Catagni, M. A. The Ilizarov method for failed knee arthrodesis following septic TKR. Knee. (2001). Jun;, 8(2), 135-8. 
[10] Rao, M. C, Richards, O, Meyer, C, \& Jones, R. S. Knee stabilisation following infected knee arthroplasty with bone loss and extensor mechanism impairment using a modular cemented nail. Knee. (2009). Dec; , 16(6), 489-93.

[11] Neuerburg, C, Bieger, R, Jung, S, Kappe, T, Reichel, H, \& Decking, R. Bridging knee arthrodesis for limb salvage using an intramedullary cemented nail: a retrospective outcome analysis of a case series. Arch Orthop Trauma Surg. (2012). May 13.

[12] Dawson, J, Fitzpatrick, R, Murray, D, \& Carr, A. Questionnarie on the perceptions of patients about total knee replacement. J Bone Joint Surg (Br) (1998). B: 63-9., 80.

[13] Klinger, H. M, Spahn, G, Schultz, W, \& Baums, M. H. Arthrodesis of the knee after failed infected total knee arthroplasty. Knee Surg Sports Traumatol Arthrosc. (2006). May;, 14(5), 447-53.

[14] Sierra, R. J, Trousdale, R. T, \& Pagnano, M. W. Above-the-knee amputation after a total knee replacement: prevalence, etiology, and functional outcome. J Bone Joint Surg Am. (2003). Jun; A(6):1000-4., 85.

[15] Fedorka, C. J, Chen, A. F, Mcgarry, W. M, \& Parvizi, J. Klatt BA Functional ability after above-the-knee amputation for infected total knee arthroplasty. Clin Orthop Relat Res. (2011). Apr; , 469(4), 1024-32.

[16] Falahee, M. H, Matthews, L. S, \& Kaufer, H. Resection arthroplasty as a salvage procedure for a knee with infection after a total arthroplasty. J Bone Joint Surg Am. (1987). , 69, 1013-21.

[17] Barrack, R. L, Engh, G, Rorabeck, C, et al. Patient satisfaction and outcome after septic versus aseptic revision total knee arthroplasty. J Arthroplasty 15:990, (2000).

[18] Benson, E. R, Resine, S. T, \& Lewis, C. G. Functional outcome of arthrodesis for failed total knee arthroplasty. Orthopedics. (1998). , 21, 875-9.

[19] Kilgus, D. J, Howe, D. J, \& Strang, A. Results of periprosthetic hip and knee infections caused by resistant bacteria. Clin Orthop Relat Res. (2002). Nov;(404):116-24.

[20] Wiedel, J. D. Salvage of infected total knee fusion: the last option. Clin Orthop Relat Res. (2002). Nov;(404):139-42.

[21] Naranja RJ JrLotke PA, Pagnano MW, Hanssen AD. Total knee arthroplasty in a previously ankylosed or arthrodesed knee. Clin Orthop. (1996). , 331, 234-7.

[22] Clemens, D, Lereim, P, \& Holm, I. Reikerås O Conversion of knee fusion to total arthroplasty: complications in 8 patients. Acta Orthop. (2005). Jun;, 76(3), 370-4.

[23] Phillips, H. T, \& Mears, D. C. Knee fusion with external skeletal fixation after an infected hinge prosthesis: a case report. Clin Orthop Relat Res. (1980). Sep;(151):147-52.

[24] Garberina, M. J, Fitch, R. D, Hoffmann, E. D, Hardaker, W. T, Vail, T. P, \& Scully, S. P. Knee arthrodesis with circular external fixation. Clin Orthop Relat Res. (2001). Jan;(382): 168-78. 
[25] Vanryn, J. S, \& Verebelyi, D. M. One-stage débridement and knee fusion for infected total knee arthroplasty using the hybrid frame. J Arthroplasty. (2002). Jan; 17(1), 129-34.

[26] Wilde, A. H, \& Stearns, K. L. Intramedullary fixation for arthrodesis of the knee after infected total knee arthroplasty. Clin Orthop Relat Res. (1989). Nov;(248):87-92.

[27] Gore, D. R, \& Gassner, K. Use of an intramedullary rod in knee arthrodesis following failed total knee arthroplasty. J Knee Surg. (2003). Jul;, 16(3), 165-7.

[28] MacDonald JHAgarwal S, Lorei MP, Johanson NA, Freiberg AA. Knee arthrodesis. J Am Acad Orthop Surg. (2006). Mar;", 14(3), 154-63.

[29] Talmo, C. T, Bono, J. V, Figgie, M. P, Sculco, T. P, Laskin, R. S, \& Windsor, R. E. Intramedullary arthrodesis of the knee in the treatment of sepsis after TKR. HSS J. (2007). Feb; 3(1), 83-8.

[30] Schoifet, S. D, \& Morrey, B. Persistent infection after successful arthrodesis for infected total knee arthroplasty. A report of two cases. J Arthroplasty. (1990). Sep; 5(3), 277-9.

[31] Knutson, K, Hovelius, L, Lindstrand, A, \& Lidgren, L. Arthrodesis after failed knee arthroplasty. Clin Orthop. (1984).

[32] Elligsen, D. E. Rand, JA Intramedullary arthrodesis of the knee after failed total knee arthroplasty. J Bone Joint Surg (1994). A:870-877., 76.

[33] Mazet R JrUrist MR. Arthrodesis of the knee with intramedullary nail fixation. Clin Orthop. (1960). , 18, 43-53.

[34] Knutson, K, \& Lidgren, L. Arthrodesis after infected knee arthroplasty using an intramedullary nail. Reports of four cases. Arch Orthop Trauma Surg. (1982). , 100(1), 49-53.

[35] Jorgensen, P. S, \& Torholm, C. Arthrodesis after infected knee arthroplasty using long arthrodesis nail. A report of five cases. Am J Knee Surg. (1995). , 8, 110-3.

[36] Bargiotas, K, Wohlrab, D, Sewecke, J. J, Lavinge, G, Demeo, P. J, \& Sotereanos, N. G. Arthrodesis of the knee with a long intramedullary nail following the failure of a total knee arthroplasty as the result of infection. Surgical technique. J Bone Joint Surg Am. (2007). Mar;89 Suppl 2 Pt., 1, 103-10.

[37] Waldman, B. J, Mont, M. A, Payman, K. R, Freiberg, A. A, Windsor, R. E, Sculco, T. P, \& Hungerford, D. S. Infected total knee arthroplasty treated with arthrodesis using a modular nail. Clin Orthop. (1999). , 367, 230-7.

[38] Mcqueen, D. A, Cooke, F. W, \& Hahn, D. L. Knee arthrodesis with the Wichita Fusion Nail: an outcome comparison. Clin Orthop Relat Res. (2006). May;, 446, 132-9.

[39] Iacono, F, \& Bruni, D. Lo Presti M, Raspugli G, Bondi A, Sharma B, Marcacci M. Knee arthrodesis with a press-fit modular intramedullary nail without bone-on-bone fusion after an infected revision TKA. Knee. (2012). Oct;Epub 2012 Feb 15., 19(5), 555-9. 
[40] Hinarejos, P, Ginés, A, Monllau, J. C, Puig, L, \& Cáceres, E. Fractures above and below a modular nail for knee arthrodesis. A case report. Knee. (2005). Jun; 12(3), 231-3. 